\title{
EDITORIAL
}

\section{Dialysis Adequacy - a Difficult Challenge}

Hemodialysis is the most common renal replacement therapy in the world, and hemodialysis adequacy is an important and influential factor in the reduction of various complications experienced by dialysis patients. Adequacy of dialysis is a term that has been used for many years based on measurement of small solute clearance using urea and creatinine. Multiple factors influence hemodialysis adequacy eg. Economy,distance of dialysis centre,co-morbidities of patients, supervision of nephrologists etc. The concept of quality, adequacy, or appropriateness of hemodialysis which were introduced in the 1970s, implies dialysis which enables patients to have a normal quality of life as well as clinical tolerance with minimal problems during the dialysis and interdialysis periods. Quantification of the dialysis dose is an essential element in the management of chronic HD treatment because the adequacy of the dose has a profound effect on the patient morbidity and mortality.

To ensure a sufficient dialysis, the delivered dose should be measured and monitored routinely. Urea kinetic modelling (UKM)is the best method for routine measurement of the dose of haemodialysis. UKM is assessed by several indicators such as percent reduction of urea during dialysis (URR), total clearance of urea normalized for distribution volume $(\mathrm{Kt} / \mathrm{V})$, protein catabolic rate (PCR) and time average concentration of urea (TAC) and these are calculated with mathematical formulas. Adequacy of hemodialysis improves patient survival, quality of life and biochemical outcomes and minimizes disease complications and hospitalizations.

Individualizing the hemodialysis prescription based on monthly assessment of single-pool Kt/V would be a useful and practical tool to provide a safe and costeffective hemodialysis treatment. The National Kidney Foundation Disease Outcomes Quality Initiative (KDOQI) guidelines recommend that the minimum adequate dose of hemodialysis given three times per week to patients with $\mathrm{Kr}$ less than $2 \mathrm{~mL} / \mathrm{min} / 1.73$ $\mathrm{m} 2$ should be a single-pool Kt/V of 1.2 per dialysis. For treatment times less than $5 \mathrm{~h}$, an alternative minimum dose is a urea re-duction ratio (URR) of $65 \%$.
Most of the studies adequacy of dialysis refers to biochemical outcome measures, most of which are not related with patient relevant outcomes. For patients, adequate dialysis is a dialysis that enables them to spend as much quality time in their life as possible.

In this issue of BCPS journal, Rasul et al conducted a study over 137 patients in the dialysis center of Combined Military Hospital (CMH) Dhaka to determine adequacy of hemodialysis. Only $21 \%$ had adequate dialysis in the group of 8 hours per week hemodialysis and in the group of 12 hours per week hemodialysis, 43 $\%$ had good dialysis. Patients who achieve target spKt/ $\mathrm{V}$ also achieve target URR and was statistically significant. URR, TAC urea and $\mathrm{nPCR}$ was significantly better in patients with $\mathrm{spKt} / \mathrm{V}>1.2$ group. The study also found that patients who do there dialysis with blood flow more than $250 \mathrm{ml} / \mathrm{min}$ had significantly better dialysis adequacy.

This study is from a single center and the sample size was also small, as such the result may not reflect the exact picture of whole country. Further studies could be undertaken including a large number of patients from different hospitals of different districts of the country so that overall national consensus about hemodialysis prescriptions could be made.

(J Bangladesh Coll Phys Surg 2019; 37: 165-166) DOI: http://dx.doi.org/10.3329/jbcps.v37i4.43343

\section{Mamun Mostafi ${ }^{1}$, Masrura Jabin ${ }^{2}$ \\ Gonoshasthaya Somaj Vittik Medical College and Gonoshasthaya Nogor Hospital}

\section{References:}

1. Steyaert, Sanne, et al. "Reporting of 'Dialysis Adequacy' as an Outcome in Randomised Trials Conducted in Adults on Haemodialysis." Plos One, vol. 14, no. 2, 2019, doi:10.1371/journal.pone.0207045.

2. Anandh, U., K. Jayanna, K., Birajdar1, N., "Mon-088 Factors Affecting Dialysis Adequacy And The Effect Of Dialysis Shift Time On Adequacy." Kidney International Reports, vol. 4, no. 7, 2019, doi:10.1016/j.ekir.2019.05.878. 
3. Saha, S., Islam, R., Rahim, M. A., Chowdhury, T., Razzak, A., Latif, A., Ananna, M., Iqbal, M., Mansur, M. A., Choudhury, A., \& Iqbal, S. (2019). Dialysis Adequacy and Quality of Life in Diabetic and Non-diabetic Bangladeshi Patients on Maintenance Hemodialysis. BIRDEM Medical Journal, 9(2), 138-146. https://doi.org/10.3329/ birdem.v9i2.41280

4. Rezaiee O, Shahgholian N, Shahidi S. Assessment of hemodialysis adequacy and its relationship with individual and personal factors. Iran J Nurs Midwifery Res. 2016;21(6):577-582. doi:10.4103/1735-9066.197673

5. Adas H, Al-Ramahi R, Jaradat N, Badran R. Assessment of adequacy of hemodialysis dose at a Palestinian hospital. Saudi J Kidney Dis Transpl [serial online] 2014 [cited 2019 Sep 22];25:438-42. Available from: http://www.sjkdt.org/ text.asp?2014/25/2/438/128615
6. Biniaz, V., Moonaghi, H. K., Froutan, R., \& Ebadi, A. "Subjective adequacy of dialysis; a neglected concept in hemodialysis adequacy.", Journal of Renal Injury Prevention, 7(3), 164-170. (2018)

7. USRDS (US Renal Data System), “Annual Data Report: Atlas of End-Stage Renal Disease in the United States", Bethesda, National Institutes of Health, National Institute of Diabetes and Digestive and Kidney Diseases; 2016:23

8. Kailash Jindal, Christopher T. Chan, Clement Deziel, David Hirsch, Steven D. Soroka, Marcello Tonelli, Bruce F. Culleton. "CHAPTER 1: Hemodialysis Adequacy in Adults". JASN Mar 2006, 17 (3 suppl 1) S4-S7;

9. Chan, Christopher T.Abu-Alfa, Ali K. et al. "Dialysis initiation, modality choice, access, and prescription: conclusions from a Kidney Disease: Improving Global Outcomes (KDIGO) Controversies Conference", Kidney International, Volume 96, Issue 1, 37 - 47 